\title{
Towards Integral Human-Machine System conception: from automation design to usability concerns
}

\author{
Pere Ponsa
}

Ramon Vilanova

Beatriz Amante

\begin{abstract}
The purpose of this communication is to show an additional advantage of the well known guide for start and stop modes, GEMMA, that should motivate its use as well as to introduce the consideration of the human operator as an integral part of the automation procedure. The inclusion of the human operator as well as his interplay with the automation device needs some guidelines that can be drawn from joining the GEMMA structured approach and some concepts borrowed from cognitive ergonomic theory and human-computer interaction. Finally, this paper shows some examples of humanmachine interfaces (industrial panel, interface display screen).

Keywords: Automation, Supervisory Control, Display Design, Human Computer Interaction
\end{abstract}

\section{INTRODUCTION}

The increased complexity of industrial process control needs calls for a new methodological approach (for research and design purposes), which reproduces the essential components of current control systems: the environment, the task at hand and human operator activity. The complexity of industrial process supervision makes it necessary to supplement the Human Factors approach and the Human-Computer Interaction approach with a crossdisciplinary cooperation in order to integrate knowledge and methods from other fields, especially Cognitive Ergonomics, Automation and Artificial Intelligence [14]. Our view is that complete control systems engineering must encompass all these approaches.

The design of increasingly complex production systems has called for new automation design tools. On the academic side different tools have been developed to tackle such problems. Among them Petri Nets (PN) have proved to be a successful approach on a broad range of applications [4]. There is however one point that is not clear how to deal with within the PN formalism: the introduction of the operator. Effectively, in every automation problem the fully automated part is just one part of the solution. It is customary that the operator can enter the loop in different ways, and such interaction needs to be considered as an integral part of the automation procedure as well as the communication of the automation device (usually a

Pere Ponsa is with the Technical University of Catalonia, Department of Automatic Control, Av. Vctor Balaguer s/n, 08800 Vilanova i la Geltr, Barcelona, Spain E-mail: Pedro.Ponsa@upc.edu

Ramon Vilanova is with the Department of Telecomunications and Systems Engineering at the Universitat Autonoma de Barcelona ETSE, Campus UAB, 08193, Bellaterra, Barcelona, Spain E-mail: Ramon.Vilanova@uab.cat

Beatriz Amante is with the is with the Technical University of Catalonia, Department of Engineering Projects, Colom 11, Terrassa, Spain E-mail: Beatriz.Amante@upc.edu
(PLC) Programmable Logic Controller) with the operator. A Human Machine Interface (PC display, Industrial Panel) provides the connection between the human operator action and the input to algorithm control inside the controller (control based PC, control based PLC).

On the other side, the industrial counterpart said that other approaches than PN are currently in use. Effectively, even PN allow tackling really large and complex problems, other approaches like Sequential Flow Charts SFC or StateTransition Graph (GRAFCET) can be considered the primary automation design tool found on industry. In fact, some of the today existing PLCs allows direct programming by using GRAFCET [2].

Therefore it seems there is a gap between both of these approaches. What we would like to point out here is that both disciplines should be combined and used. The important point with GRAFCET, is even a simpler approach if compared with PN, is that it has a close and clear connection with the design guide for start and stop modes called GEMMA [1]. Even the GEMMA guide started to be used twenty-five years ago and it is introduced to the engineering students in several places but the authors opinion is that we need to paid more attention to GEMMA guide. This is the reason this paper would like to focus on advantages of using GEMMA guide.

Although GRAFCET is very useful in describing the detailed operation of a sequential control performed by a PLC it does not provide a general approach for the operation of an automated machine. It is still necessary to define general operational modes and conditions. This is usually done at the specifications definition stage. In this sense, GEMMA is a recommended tool for this task [8].

On the other hand, it has always been difficult in terms of vocabulary to clearly, and precisely, explain how to start with manual mode or a semi-automatic mode or an automatic mode. Also what are the consequences of an emergency stop, a safety stop or a fast stop for production machines. Usually, these questions are answered by each designer in relation to his own experience and knowledge but can seldom be related to systematical analysis, except in large companies which have been able to define design guide and standards for control and instrumentation.

From the previous observations, fig. 1 presents GEMMA guide as a valuable tool to introduce automation in a more 


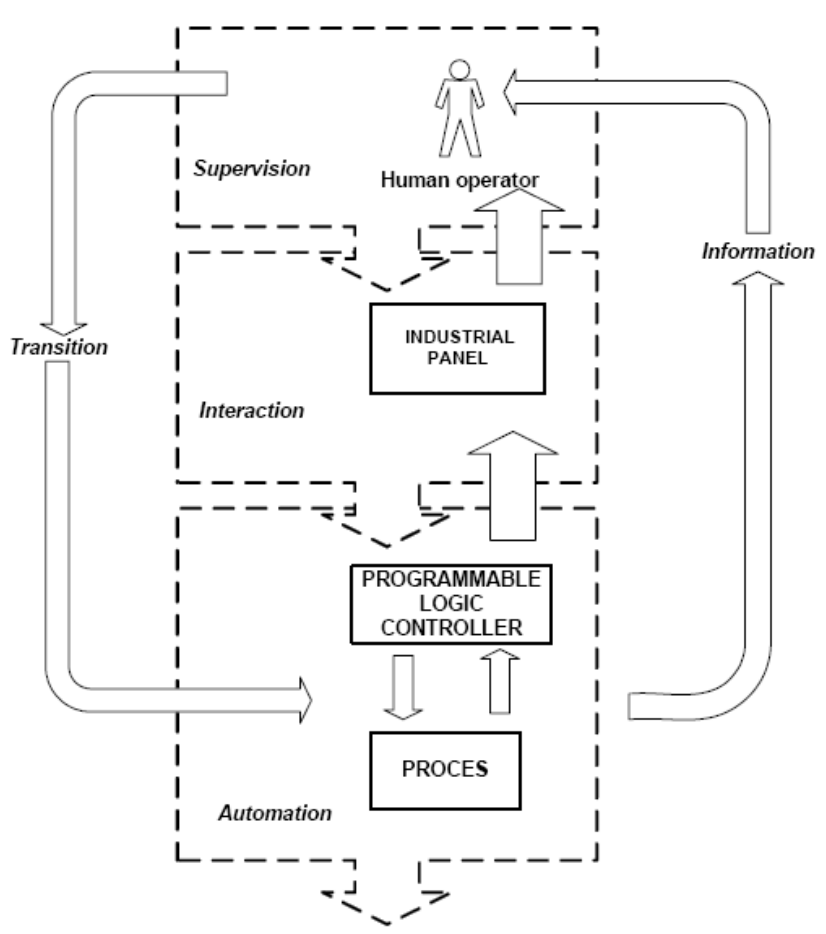

Fig. 1. Human machine system from the point of view of GEMMA guide in automation.

general setting than only for automatization the process production cycle. It is really important to understand the role played by the operator and how he interacts with the automated system [5]. The different operation modes need to be established and interact in a clear and well defined way.

The main contribution of this paper is to advance one step towards an integral conception of the automation process: the design of the automation system has to include considerations on operational modes and these have to be reflected into the human interface. The proposed approach uses the well known GEMMA guide as the central point, as the GEMMA guide allows; by a precise definition of the operational modes; an structured conception of the automation programs that can be inherited into the human interface. In this sense a generic industrial panel is proposed that reflects such operational modes. A physical prototype has been done in order to perform usability experiments.

The paper is structured as follows. The second section of the paper presents a set of guidelines in the design of a panel, to facilitate human intervention, inherited from the application of the GEMMA guide in industrial/academic domain. The third section presents an application over an educational manufacturing system in order to exemplify the differences between the generic HMI panel and the one conceived from the application of the outlined GEMMA guide. The fourth section presents a set of ergonomic guidelines in the design of a display in industrial control room and extends the designed panel introducing it into the control room by using a SCADA system, for example. Finally the conclusions are presented.

\section{GEMMA GUIDE BASED INDUSTRIAL PANEL DESIGN}

In industrial automation engineering there is a wide range of devices that belong to HMI (human-machine interfaces) [3][6]. In this paper we will focus on industrial panel design applying the prescriptions from the GEMMA guide. This operator awareness of interaction processes is crucial in order to the classify system states and events, to process information and plan consistent interventions.

In industrial applications basic industrial panels may be placed on machines or raised to the level of operator sight. If the machine has many peripheral components there would usually be many industrial panels with several devices (visual information, switches, and selectors) with different functions such as starting industrial conveyor, monitoring an assembly substation or managing the activities on a CNC machine. The vertical panels placed at operator sight level include multiple elements, such as switches, led pilot lights, function mode selectors, and other state information indicators. Sometimes there are also visual information devices represented by columns of leds and banks (with fixed or flashing lights) and/or acoustic signals (buzzers or sirens) [10]. It is important that the design of context interfaces would be possible to be based on identifying the classes of situations that human operators have to deal with. A prototype of a human-machine interface (industrial panel) was developed [7]. Diverse design iterations were completed, using a user centered system design approach over an academically flexible manufacturing system. In this paragraph we expose some prescriptions for industrial panels design [12], [13]. A basic rule is to avoid ambiguity. An industrial panel without a clear layout may provoke hesitation or misunderstanding of important information that could eventually lead to errors in control tasks.

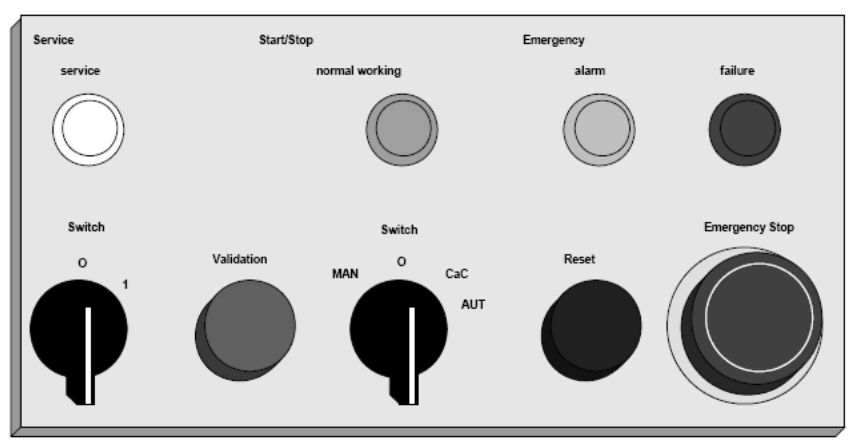

Fig. 2. Ergonomic industrial panel

Fig 2 shows a ergonomic industrial panel with a top level with visual information devices (leds) and a down level with control switches: 
The visual information devices are:

- White led: machine with energy

- Green led: normal function

- Yellow led: precaution

- Red led: abnormal function.

The control switches are:

- Mode selector: machine with or without energy

- Validation switch to validate an operator's action

- Mode selector: automatic mode AUT, manual mode MAN, a stop request to the end of the automation cycle $\mathrm{CaC}$

- Reset switch to drive the system from an abnormal function to a normal function

- Emergency stop switch: human operator can stop the machine and the controller in a dangerous situation.

From left to right the panel shows clearly the diverse operation modes:

- Service mode: machine with or without energy

- Manual/automatic mode: the control is manual (human operator actions) or automatic (controller actions)

- Security mode: an emergency stop and a reset switch

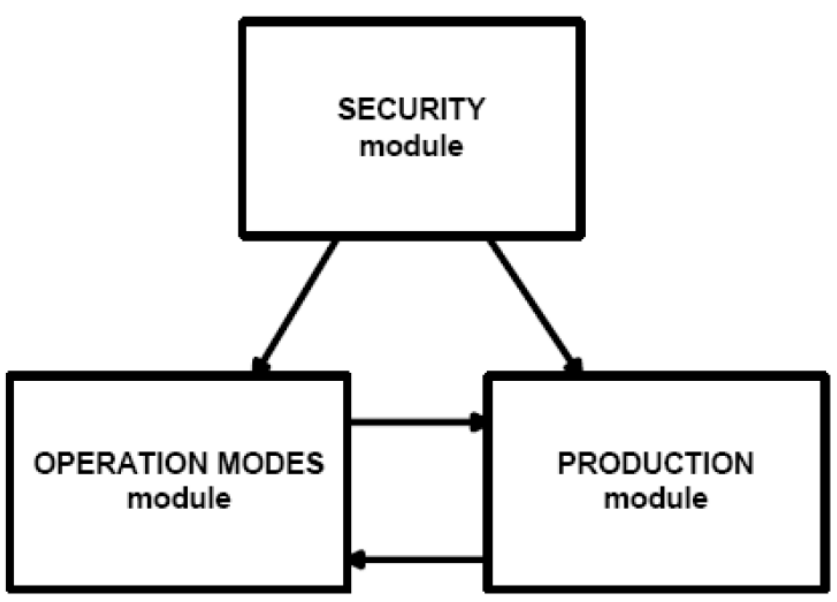

Fig. 3. GEMMA Modular approach of automation design

These operation modes are directly inherited from the design that arises from the application of the GEMMA guide in order to develop the automation of the process at hand by means of a GRAFCET-like solution. Roughly speaking we can identify the following three modules when dealing with the design of an automated system:

- Security module.

- Operation Modes module.

- Production module.

The representation used within GEMMA takes into account these modules as well as the internal relations among them. The hierarchy shown in Fig 3 tries to stress the security aspects of automated production systems. This will be the case in an emergency situation, device failure, or even when the production system without reason is not generating the product properly [4]. Under these situations the Security module has higher priority over the other modules in order to take the appropriate decision. It is also worth to notice the introduction of the operator as an integral part of the system. The operator adds experience in the switch from automatic to manual operation modes. This way the global control of the process can be the result of an intermittent actuation between the Manual mode and the automated mode. The Production module appears hierarchically under the previous ones. This module is the responsible for the sequential operation of the production process and operates on the basis of the state of the other modules.

\section{FRAMEWORK FOR TESTING THE DESIGN: EDUCATIONAL MANUFACTURING SYSTEM}

At Universitat Autnoma of Barcelona and at Technical University of Catalonia, the programs degree focus in different subjects like: Industrial Automation, robotics Modeling and Simulating Systems and Integrated Production Systems. These subjects make a special emphasis on technical topics of controllers (programmable logic controllers-PLCs) and industrial handler robots. The practical content is developed by working on a educational Flexible Manufacturing System. The fig. 4 shows the physical distribution of the stations in the used educational manufacturing system. The flexible cell is composed of electro-pneumatic units controlled by PLCs and PCs. The main activity consists in emulating current manufacturing systems: object mechanization and supply, transfer, product assembling, quality control, checking and storage; and technologies, such as, pneumatics, robotics, PLC, monitoring and production supervision come together:

- Station 1: Feeding, detection and distribution of items.

- Station 2: Mechanization (only emulated) and item checking.

- Station 3: Quality control by means of a Webcam

- Station 4: Item and/or product assembling, palletization, and handling by means of a robot

- Station 5: Closed-square belt conveyor system with continuous loop and cue management with pneumatic mechanisms for blocking.

The flexible manufacturing system is an example of a distributed system. Each station has a local controller and a especific industrial panel initially installed on it. This industrial panel was already supplied as part of the educational system. Fig. (5) shows that panel's configuration. We can see in this figure from left to right:

- MAN/AUT is the manual/automatic mode selector

- MARCHA is the switch to run the automation cycle

- IND/INT is a mode selector to decide if the Station works alone or integrated with the other stations of the flexible manufacturing system 


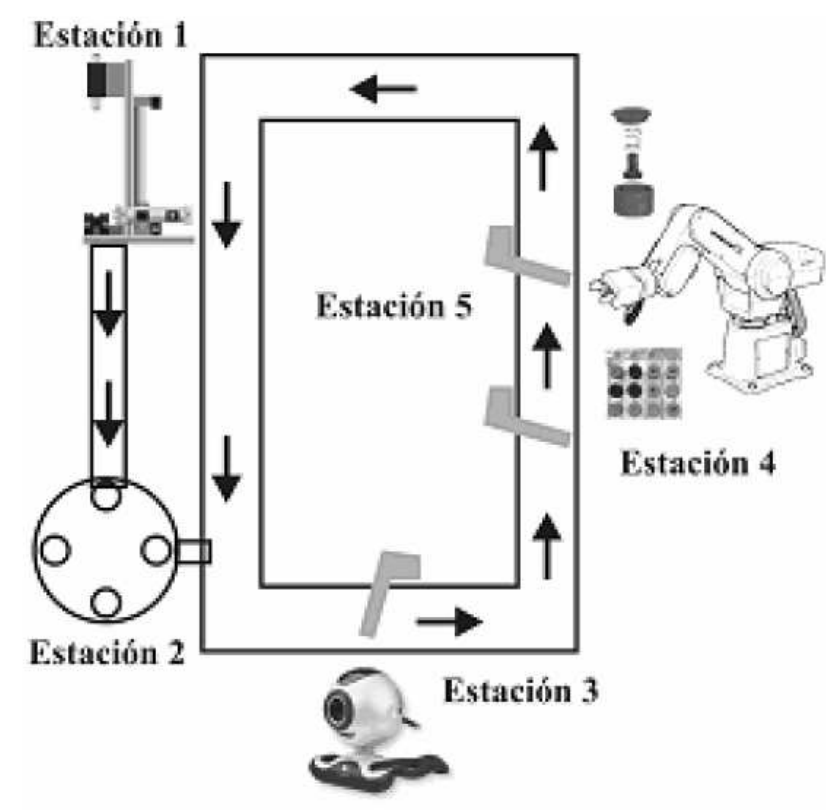

Fig. 4. A flexible manufacturing system with five stations (Estacion in Spanish version)

- RESET is the reset switch

- EMERGENCIA is the emergency stop switch

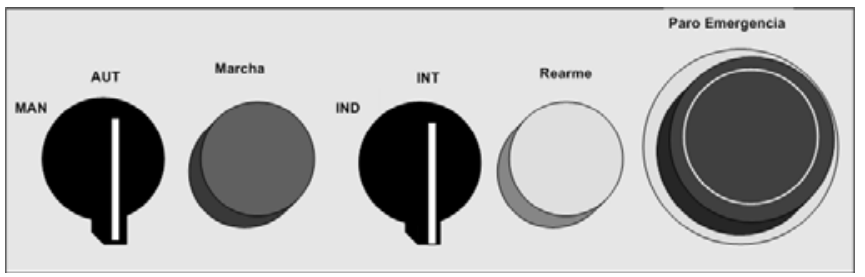

Fig. 5. Industrial panel initially present at the Flexible Manufacturing System Stations

This flexible manufacturing system provides the framework for the application of the GEMMA guide ideas for HMI design. A team of Technical Engineers are asked to apply the GEMMA guide to each station of the manufacturing system with the purpose of automating the corresponding task. They are asked to perform:

- The Programmable Logical Controller's selection

- Creation of the graphic representation of the GEMMA guide GEMMA and creation of the GRAFCET of the station

- Programming of the algorithm inside the controller

- Test of the use of the industrial panel manufactured by the commercial distributor (see fig. 4), and test of the use of the GEMMA guide

- Proposal of improvements.

The Engineers team proceeds to the intervention by means of the industrial panel of fig. (5). The advantages, inconveniences and the assessment in the use of the industrial panel are commented in the role of users for the improvement of panel's design. The advantages of the panel from the point of view of the commercial usage are: low cost, possibility of either autonomous work or integrated among stations, and risk assessment with emergency stop and reset switch. The advantages observed in this panel from the point of view of the technical engineers are: easy to learn how to use it as well as easy physical connectivity with the controller.

The disadvantages verified by the technical engineers and gathered in a project during 6 months are difficulty of implementation of all the situations contemplated in the GEMMA guide and absence of visual information display (leds). The engineers use this control panel to present a series of improvements to include in the design of a future control panel using the human-station cooperation. The fig. (6) shows a set of visual indicators and a new set of switches for the manual (human) control of pneumatic actuators of the station.

In this sense, the authors of this work asses the specifications of the technical engineers, in the role of users, and the specifications in ergonomic design of the previous section to note that:

- The proposed panel shows ambiguity. It must organize the panel and distinguish between visual information leds and switches

- It must increase the presence of visual information devices

- In an industrial sector the human operator can contribute with his experience to the designer of the control panel to discuss or to find the best location of the visual indicators and switches.

Fig. (7) shows the definitive version of the control panel. In spite of the increment complexity of the control panel regarding the one represented in fig. (5), it is needed to indicate that it must add a new function called Verification, and a new zone in the panel. The human operator can select manual operational mode and choose the Verification function to test the normal functioning of the actuators of the station. The Verification function is an example of preventive maintenance of station.

As a final result of the new proposal for the industrial panel and the verification of the advantages of linking its design with the operational modes that arise from the application of the GEMMA guide, a physical prototype has been developed and is being now used for tests and experiences (See fig. (8)

\section{SCADA INTERFACE}

To go one step forward, the proposed industrial automation panel is to be introduced as part of a SCADA (supervisory control and data acquisition software) interface. By using commercial SCADA software it is possible to create a 


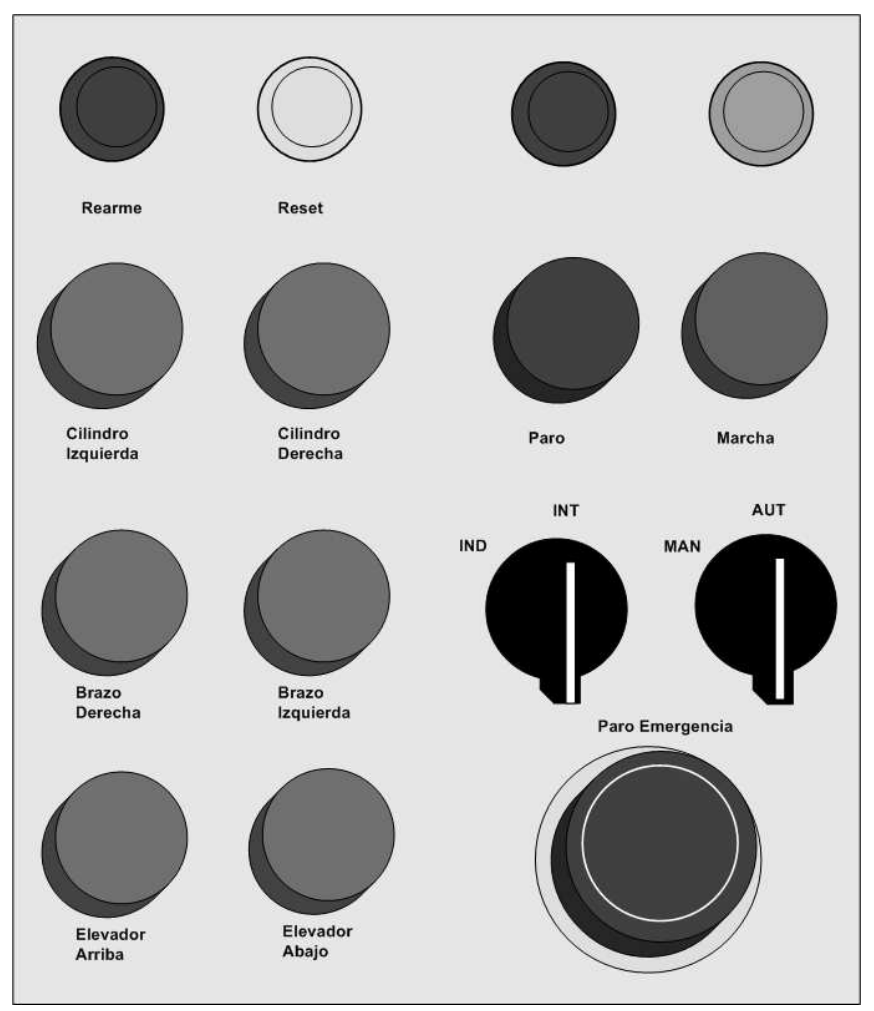

Fig. 6. Technical Engineers proposed panel

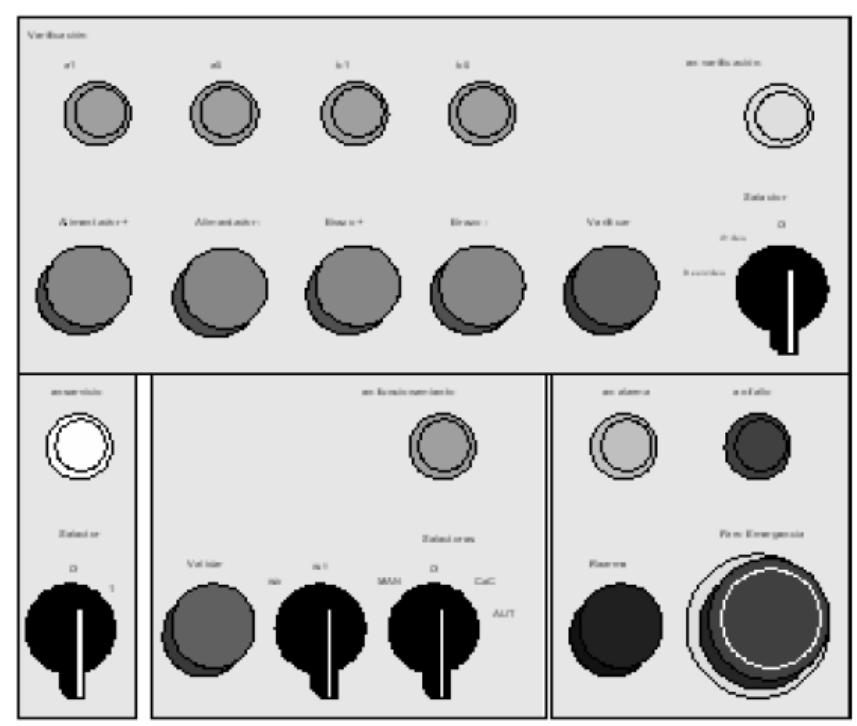

Fig. 7. The authors' panel with ergonomic specifications and a new function (verification) at the top of the panel.

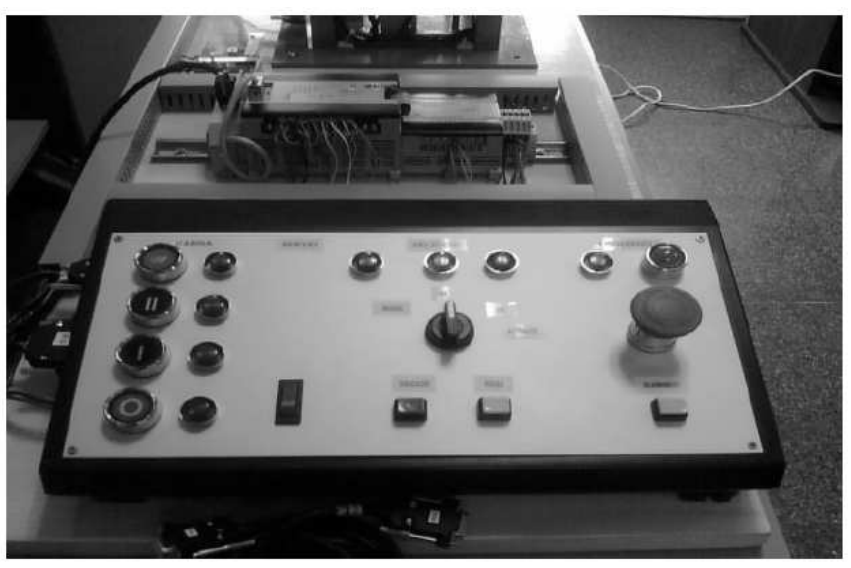

Fig. 8. Real prototype according to the GEMMA guide operational modes

display screen like the ergonomic industrial panel of the fig. (2) (see fig. (10)). One advantage in the use of SCADA software is the possibility to integrate surveillance, control and maintenance in just one software application. In the case of the educational manufacturing system with n-stations, it's possible to create an SCADA interface with n-screens in order to maintain the same architecture of the physical layout.

It must incorporate considerations for the human interaction with the supervisory control interface. This task is accomplished by introducing a human factors guideline for supervisory control interface design [8] in order to create a display design of the industrial panel inside the supervisory control software. The GEDIS guide ('Ergonomic Guideline for Supervisory Control Interface Design' ${ }^{1}$ ) consists of ten indicators that seek to cover all aspects of the interface design in the supervisory control domain [8]. The indicators are: architecture, distribution, navigation, color, text font, status of the devices, process values, graphs and tables, data-entry commands, and alarms.

As an example, the distribution indicator of fig. (9) shows a possible layout to locate all the objects inside the screen. The object's homogeneous distribution allows us to maintain the interface coherence when the user changes the screen. The secondary objects are located in screen areas that don't require the user's attention (enterprise logo, and date/hour information). The user should recognize the screen title and the general navigation tool to move among screens. The main objects are located in visible screen areas (alarms, data-entry commands, sub navigation tool, and synoptic objects). The user can watch the process evolution without acting (human out of the loop), or he can decide to introduce changes in the set point or in the controller's parameters (human in the loop) inside a faceplate window in the data-entry command object. The user should pay special attention to the alarm indicators, which should be

${ }^{1}$ GEDIS - Guia Ergonmica para el Diseo de Interfaz de Supervision in Spanish version 


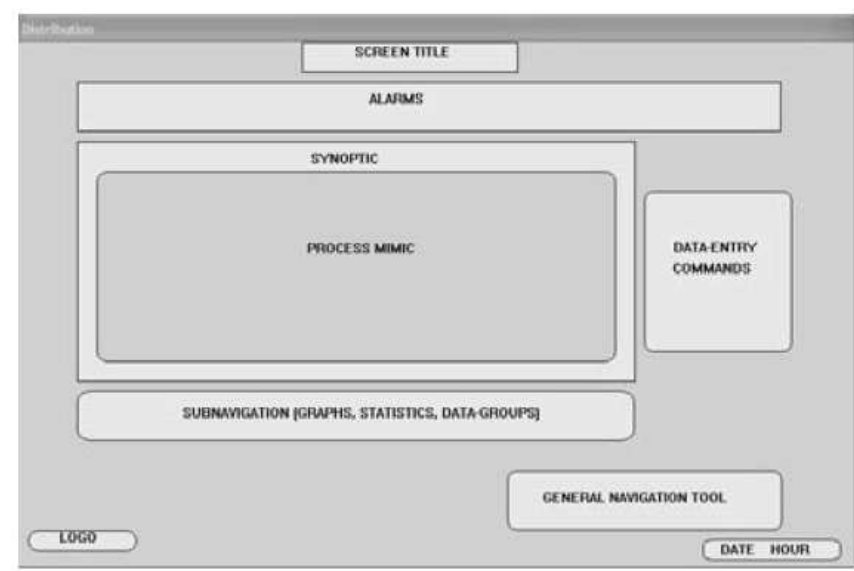

Fig. 9. An example of object's layout inside the screen for the distribution indicator.

located in a clear way in the screen so that the user can recognize the situation (situation awareness).

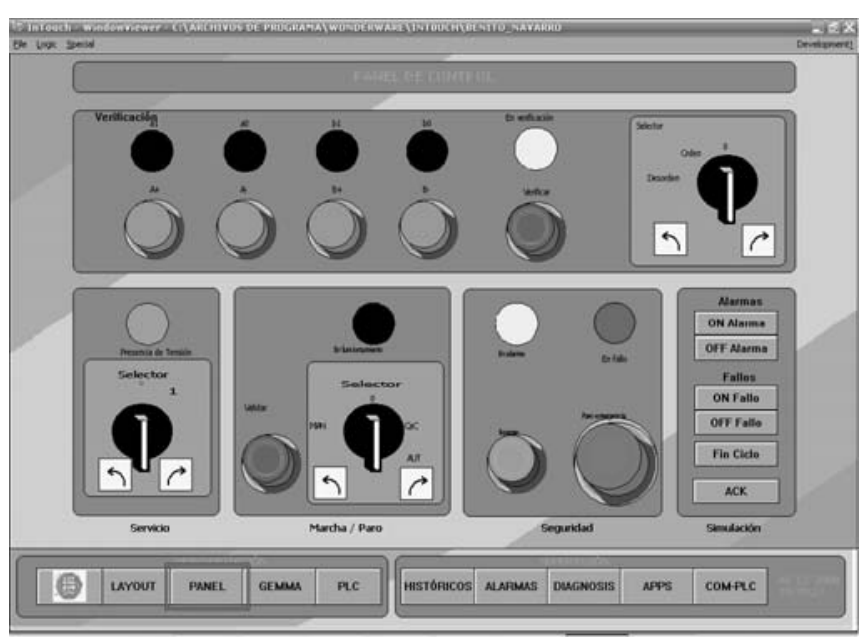

Fig. 10. The ergonomic industrial display inside the professional SCADA Intouch by Wonderware.

The Wonderware suite includes the InControl software that allows direct implementation of Discrete Event Systems by using GRAFCET diagrams. As the designed panel arises from the operation modes of the GEMMA guide, it is possible to represent the operating mode of the process by using the corresponding GRAFCET diagram (this is known as the Conduction GRAFCET in GEMMA terminology). This way, as the operator proceeds on the process operation, the actions conducted by using the designed industrial panel are, at the same time, linked to transitions on such GRAFCET. Therefore allowing a surveillance action of the process operational state. Fig. (11) shows the SCADA window corresponding to the GRAFCET implementation of the GEMMA guide.

It is also necessary to establish a connection between the SCADA interface design and GEDIS guideline designer. This is accomplished by defining a global evaluation of the interface that can give a set of recommendations

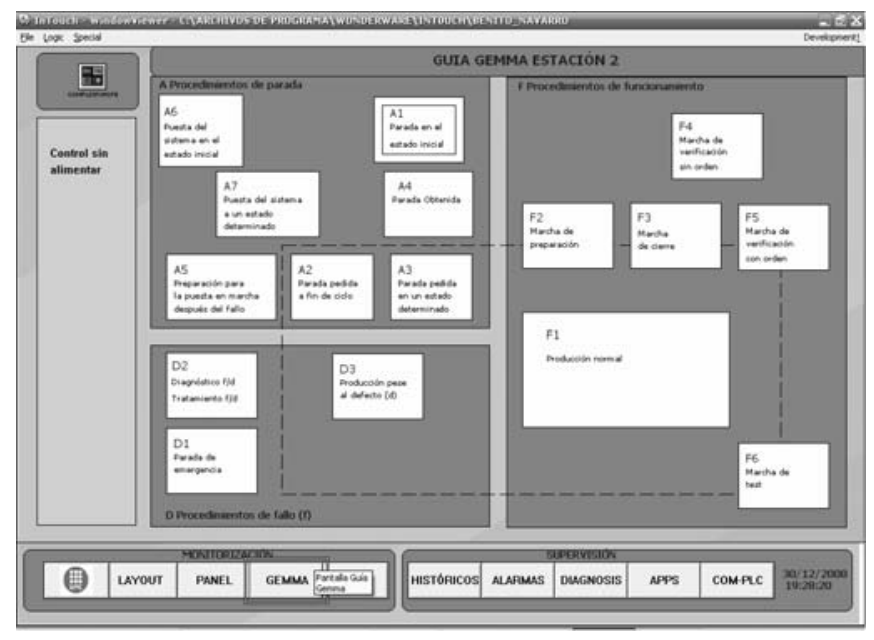

Fig. 11. Introduction of the GEMMA guide states into the Supervisory control software

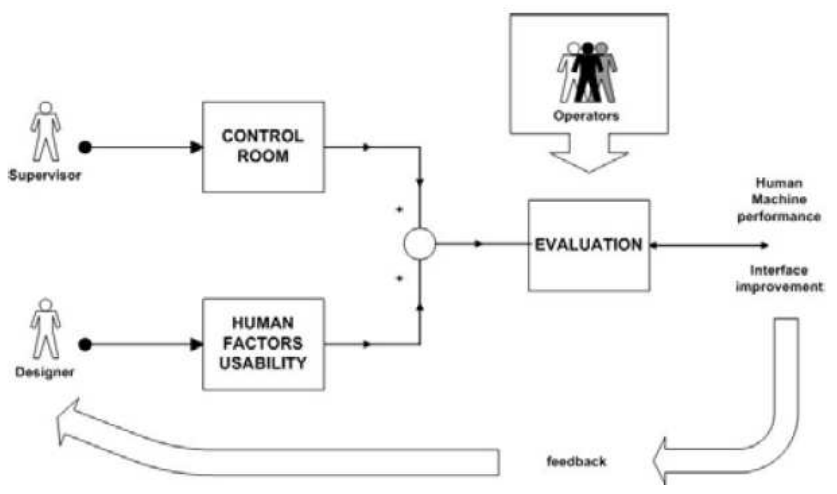

Fig. 12. An human factors and usability framework in industrial control room

about graphical screen improvement. This is the first step in the definition of a usability framework to improve control room design in automation systems (see fig. 11) [11].

\section{Summary AND CONCLUSIONS}

In this conclusion, we point at some issues of interest and conclude the study that has been presented.

The GEMMA guide approach is a recommended taxonomy approach for the introduction of the human operator into the automation cycle in complex academical/industrial domain. It provides a natural relationship between the design of the automation system and the operational modes that are to be considered from the industrial panel point of view.

The resulting panel structure is to be incorporated into an SCADA interface and ergonomically evaluated by introducing the GEDIS guideline. Both steps provide a unified framework for the interface design that ranges from the plants operator panel to the SCADA interface on a control room. The next step in this work is to perform 
experiments on a usability laboratory in order to compare the use of the initial and proposed interfaces (mental workload, performance, users' satisfaction).

\section{ACKNOWLEDGEMENTS}

This work is partially supported by the Spanish program CICYT DPI2007-63356 and the Spanish MEC project ADAEXODUS (DPI2006-15630-C02-01).

\section{REFERENCES}

[1] ADEPA. Le GEMMA. "Guide d'tude des Modes de Marches et d'Arrts". Montrouge: ADEPA, 1981.

[2] [2] AFCET-ADEPA. "Le GRAFCET". Second edition Toulouse: Cpadus, 1995. Available: http://lurpa.ens-cachan/grafcet.html

[3] D. Kee, E. S. Jung, S. Rok. "A man-machine interface model for ergonomic design". Computers and Industrial Engineering, V 27, Issue $1-4$, p. $365-368,1999$.

[4] T. Kontogiannis. "Stress and operator decision making in coping with emergencies". Int. J. Human Computer Studies, Volume 45 (I), pp. 75-104. 1996.

[5] K. Li, S. Thompson, P.A. Wieringa, J.X. Peng, "A study on the role of human operators in supervised automation system and its implications" Proceedings of the 4th World Intelligent Control and Automation, V 4, p. 3288-3293, 2002.

[6] Y. Lin, W.J. Zhang, L.G. Watson, "Using eye movement parameters for evaluating human-machine frameworks under normal control operation and fault detection situations," International Journal of HumanComputer Studies, V 59, Issue 6, p. 837-873, December 2003.

[7] P. Ponsa, M. Daz, R. Vilanova. "Ergonoma aplicada al diseo de interfaz operario-mquina en entorno industrial". CEDI2005, Primer Congreso Espaol de Informtica, Simposio S8 Interaccin Persona-Ordenador, Granada, 2005.

[8] Ponsa, Pere, Daz, Marta, 2007. Creation of an ergonomic guideline for supervisory control interface design. Engineering Psychology and Cognitive Ergonomics, Don Harris (Editor), Lecture Notes Artificial Intelligence 4562

[9] P. Ponsa, R. Vilanova, M. Daz, Inroduccin del operario humano en el ciclo de automatizacin de procesos mediante la gua GEMMA. CIT, Revista Informacin Tecnolgica, Vol 18(5), 2007. Available: http://www.citchile.cl/a1c.htm

[10] Schneider. "Human-machine interface guide", 2007. Avaliable: http://www.automation.schneider-electric.com.

[11] Schneiderman, Ben, 1997. Designing the user interface. Strategies for effective human-computer interaction. Addison-Wesley, third edition

[12] J. Rasmussen. "Information processing and human interaction. An approach to cognitive engineering". Elsevier, Amsterdam, 1986

[13] K.J. Vicente. "Cognitive work analysis". Lawrence Erlbaum associates, publishers, 1999

[14] Samad, Tariq, Weyrauch, John, 2000. Automation, control and complexity: an integrated approach. John Wiley and Sons 